\title{
Negative activation energies for carbene additions to tetramethoxyethylene
}

\author{
Lei Wang, Robert A. Moss, * Karsten Krogh-Jespersen* \\ Department of Chemistry and Chemical Biology, Rutgers, The State University of New Jersey, New \\ Brunswick, NJ 08903, United States
}

\begin{abstract}
Activation energies were determined for the additions of three arylhalocarbenes to tetramethoxyethylene (TMeOE) and tetramethylethylene (TME) in pentane and decane. For addition of 3,5-dinitrophenylchlorocarbene to TMeOE in decane, $E_{\mathrm{a}}=-10.4$ $\pm 0.7 \mathrm{kcal} / \mathrm{mol}$, the most negative activation energy yet encountered in a carbene-alkene addition reaction. Computational studies parallel and elucidate the experimental results.
\end{abstract}

Keywords: carbenes, compensation, kinetics, reactivity

The initial examples of negative activation energies in halocarbene-alkene additions were reported in 1982: additions of phenylchlorocarbene $(\mathrm{PhCCl})$ to tetramethylethylene (TME) and trimethylethylene occurred with $E_{\mathrm{a}}=-1.7 \mathrm{kcal} / \mathrm{mol}$ and $-0.77 \mathrm{kcal} / \mathrm{mol}$, respectively. ${ }^{1}$ This observation was not an isolated phenomenon; negative activation energies were subsequently measured in the additions of a variety of halocarbenes to TME in pentane. Examples include $\mathrm{CCl}_{2}\left(E_{\mathrm{a}}=-1.2 \mathrm{kcal} / \mathrm{mol}\right){ }^{2}$ pentafluorophenylchlorocarbene $\left(E_{\mathrm{a}}=-1.8 \mathrm{kcal} / \mathrm{mol}\right){ }^{3}$ and 3,5-dinitrophenylchlorocarbene $\left(E_{\mathrm{a}}=-4.7 \mathrm{kcal} / \mathrm{mol}\right){ }^{3}$ Negative activation energies of $c a .-3.5 \mathrm{kcal} / \mathrm{mol}$ were also seen in the additions of the nucleophilic hydrocarbon carbenes adamantanylidene $e^{4}$ and dimethylcarbene $e^{5}$ to the electrophilic alkene, methyl acrylate.

Two rationalizations of these negative activation energies have been provided. The first posited the reversible formation of a carbene-alkene complex, which either afforded product cyclopropane or reverted to carbene and alkene. In this case, the observed activation energy was a function of the component step-specific activation energies. ${ }^{1,6,7}$ The second model maintained that, for these reactions, the enthalpy

*Corresponding authors. Tel.: +1 848445 2606; fax: +1 7324455312 (R.A.M.); tel.: +1 848445 4241; fax: +1 7324455312 (K.K.-J.) E-mail addresses: moss@ rutchem.rutgers.edu (R.A. Moss), krogh@rutchem.rutgers.edu (K. Krogh-Jespersen) 
continuously decreased along the reaction coordinate so that $E_{\mathrm{a}}$ (and $\Delta H^{\ddagger}$ ) were negative. In contrast, $\Delta G^{\ddagger}$ was positive due to unfavorable entropic factors. ${ }^{8-10}$

Although this model specifically eschewed molecular carbene-alkene complexes, it did allow for the intermediacy of solvent cage complexes. ${ }^{8,9}$ With that possibility in mind, we examined the dependence of $E_{\mathrm{a}}$ for the $\mathrm{PhCCl}$-TME addition reaction as a function of chain length in alkane solvents. ${ }^{11} \mathrm{We}$ found that $E_{\mathrm{a}}$ decreased significantly from $-1.8 \mathrm{kcal} / \mathrm{mol}$ to $-5.2 \mathrm{kcal} / \mathrm{mol}$ as the solvent was changed from $n$-pentane to $n$ decane. We suggested that the addition reaction in decane involved solvent "cages" that limited reactant diffusion and fostered the intermediacy of PhCCl-TME proximity pairs or complexes. ${ }^{11}$ More recently, we have extended this investigation to several alkene additions of pentafluorophenylchlorocarbene $\left(\mathrm{F}_{5}-\mathrm{PhCCl}\right)$ and 3,5-dinitrophenylchlorocarbene (3,5-DN-PhCCl) with analogous results. ${ }^{12}$

Our experience suggests that negative activation energies in carbene-alkene additions can be augmented by the use of highly reactive electrophilic carbenes, very nucleophilic alkenes, and alkane solvents supportive of solvent cages (e.g. decane). Having already examined the influence of carbene electrophilicity in the $\mathrm{PhCCl}$, $\mathrm{F}_{5}-\mathrm{PhCCl}, 3,5-\mathrm{DN}-\mathrm{PhCCl}$ carbene sequence, ${ }^{3,12}$ as well as the variation of solvent chain length in the PhCCl-TME addition, ${ }^{11}$ we now turn to a study of increasing alkene nucleophilicity.

In general, the pairing of alkenes with higher-lying $\pi$-electrons (or HOMOs) and carbenes with lower-lying, more accessible LUMOs, leads to carbene-alkene cycloadditions with greater transition state stabilizations and lower activation energies. ${ }^{13}$ We therefore selected tetramethoxyethylene (TMeOE) as an alkene likely to be more nucleophilic and reactive than TME toward electrophilic carbenes.

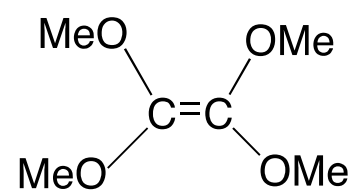

TMeOE

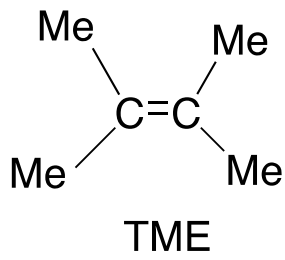

The energies of electrons in the $\pi$-orbitals of TMeOE and TME are reflected by the corresponding (vertical) ionization potentials for which measured values are reported as 
$8.00 \mathrm{eV}(\mathrm{TMeOE}){ }^{14}$ and $8.44 \mathrm{eV}$ (TME). ${ }^{15}$ Therefore, TMeOE should be somewhat more reactive than TME toward electrophilic carbenes. ${ }^{16}$

TMeOE was prepared as described in the literature. ${ }^{17} \mathrm{PhCCl}, \mathrm{F}_{5}-\mathrm{PhCCl}$, and 3,5-DN-PhCCl were generated by photolyses of the corresponding diazirines, ${ }^{3}$ and were each added to TMeOE. The anticipated tetramethoxycyclopropanes were isolated by TLC and characterized spectroscopically; see the Supplementary Data for details. TME adducts of these carbenes were known from our prior work. ${ }^{3}$

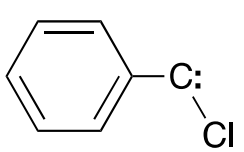

$\mathrm{PhCCl}$

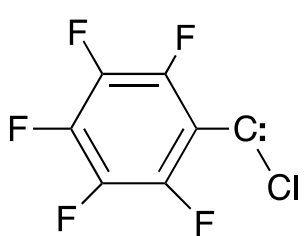

$\mathrm{F}_{5}-\mathrm{PhCCl}$

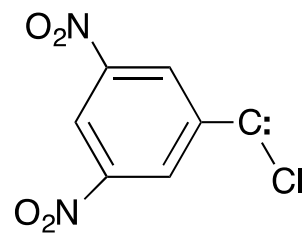

$3,5-\mathrm{DN}-\mathrm{PhCCl}$

Absolute rate constants for the additions of the three carbenes to TMeOE and TME in pentane or decane were determined by laser flash photolysis (LFP) with a xenon fluoride excimer laser emitting at $351 \mathrm{~nm} .{ }^{18}$ Observed rate constants for carbene disappearance at 5 temperatures between $275 \mathrm{~K}$ and $324 \mathrm{~K}$ were plotted against $\mathrm{TMeOE}$ or TME concentrations in either pentane or decane, and the least-squares slopes of the resulting correlations were taken as the bimolecular rate constants for the carbene-alkene additions. Further details of methodology appear in ref. 3, while the 45 new rate constant determinations appear in graphical form in Supplementary Data. ${ }^{19}$

We were sensitive to the possibility that the carbenes might react with TMeOE at oxygen, rather than at $\mathrm{C}=\mathrm{C}$. We examined this option for the addition of $\mathrm{PhCCl}$ both experimentally and computationally at the DFT level (MN12-SX/6-311+G(d)/CPCM, $n$ pentane; see the Supplementary Data for computational details). We could not locate a minimum on the $\mathrm{PhCCl}-\mathrm{TMeOE}$ potential energy surface that corresponded to a conventional $O$-ylide with a fully (or nearly fully) formed single $\mathrm{C}-\mathrm{O}$ bond. Constraining the $\mathrm{C}(\mathrm{PhCCl})-\mathrm{O}(\mathrm{TMeOE})$ separation to $1.50 \AA$, with complete relaxation of all other structural parameters, produced a structure (Figure 1a) with a potential energy ca. 5.0 $\mathrm{kcal} / \mathrm{mol}$ above that of the separated reactants (ca. $10 \mathrm{kcal} / \mathrm{mol}$ above the lowest energy 
'O-ylidic' complex, see below). TD-DFT calculations (B3LYP/6-311+G(d)) on this representative $O$-ylide structure predicted a distinct absorption with considerable intensity $(f \sim 0.18)$ peaking around $350 \mathrm{~nm}$, inside the spectral 'window region' where neither $\mathrm{PhCCl}$ nor TMeOE absorb. Despite a comprehensive search in the 300-500 nm spectral region, we detected no such electronic absorption signal.

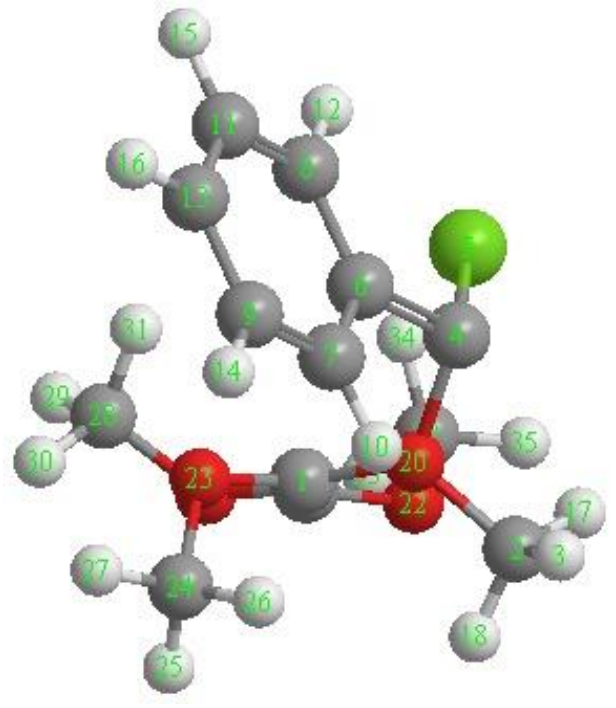

(a)

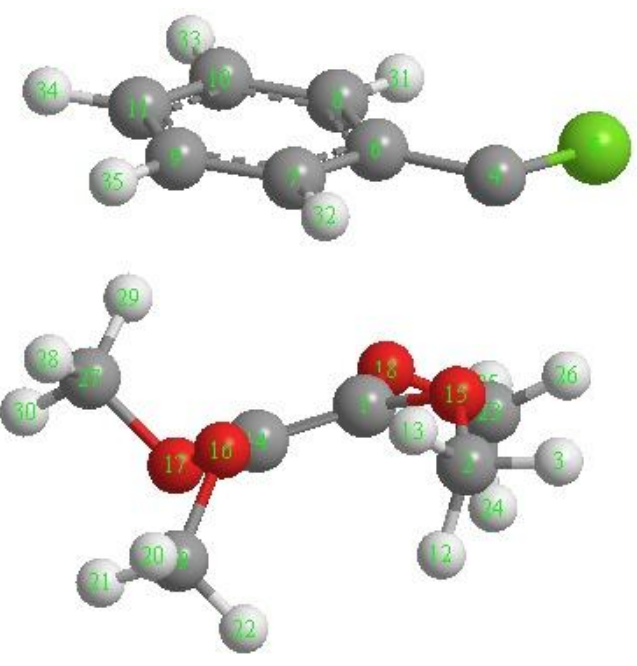

(b)

Figure 1. (a) Optimized $O$-ylide structure in which the $\mathrm{C} 4-\mathrm{O} 20$ distance was constrained to $1.50 \AA$. When the $\mathrm{C} 4-\mathrm{O} 20$ distance constraint was relaxed, the structure dissociated to $\mathrm{PhCCl}$ and $\mathrm{TMeOE}$ without passing over an energetic barrier. (b) ' $O$-ylidic' complex, computed $5.2 \mathrm{kcal} / \mathrm{mol}$ below the reactants in enthalpy. The separation C4-O15 is $2.70 \AA$. $\mathrm{C}($ alkene $)-\mathrm{C}($ aryl) nearest distances are in the 3.2-3.6 $\AA$ range.

Nevertheless, we readily located $\mathrm{PhCCl}-\mathrm{TMeOE}$ ' $O$-ylidic' type complexes in which the $\mathrm{O}(\mathrm{TMeOE})-\mathrm{C}(\mathrm{PhCCl})$ separations were in the $2.7-2.9 \AA$ range, with varying extents of overlap between the aryl ring and the ethylenic moiety (Figure 1b). However, the interaction enthalpies $(\Delta H)$ were only about $-4--5 \mathrm{kcal} / \mathrm{mol}$ for these species. Given the very unfavorable entropies of complex formation ( $\Delta S \sim-31$ to -35 e.u.), the free energies for ' $O$-ylidic' complex formation become positive $(\Delta G \sim 4-5 \mathrm{kcal} / \mathrm{mol})$, and the associated equilibrium constants are predictably quite small $\left(K \sim 10^{-3}\right)$. Thus, the ' $O$ ylidic' complexes are probably best regarded as short-lived encounter complexes. Furthermore, the $\mathrm{PhCCl}-\mathrm{TMeOE}$ interaction occurs primarily between the carbene LUMO and an oxygen lone pair and is too weak to induce any significant geometrical 
distortions in either fragment. Consequently, the electronic spectra of ' $O$-ylidic' complexes are predicted to be simple superpositions of essentially unperturbed monomer spectra with no new absorption features appearing in the spectral 'window region' of $c a$. 350-600 nm (cf. Supplementary Data).

An analogous situation pertains to the other arylhalocarbenes of interest here. Both $\mathrm{F}_{5}-\mathrm{PhCCl}$ and 3,5-DN-PhCCl may form ' $O$-ylidic' complexes with $\mathrm{TMeOE}$ that are enthalpically quite well bound (by up to $9 \mathrm{kcal} / \mathrm{mol}$ for $\mathrm{F}_{5}-\mathrm{PhCCl}$ and more than 11 $\mathrm{kcal} / \mathrm{mol}$ in the case of 3,5-DN-PhCCl), but the free energies of complex formation remain slightly positive because of the very unfavorable $-\mathrm{T} \Delta S$ contribution (ca. 10 $\mathrm{kcal} / \mathrm{mol}$ ) and equilibrium constants would necessarily be near unity. With no signature spectral features, detection of ' $O$-ylidic' complexes by electronic spectroscopy thus seems improbable.

Activation parameters for the carbene additions to TMeOE or TME in pentane or decane were derived from linear Arrhenius correlations of $\ln k$ vs 1/T ( $r>0.99)$. Their slopes and $Y$-intercepts afforded the parameters collected in Table 1, while the correlations themselves are included in Supplementary Data.

Table 1

Activation parameters for carbene additions in pentane and decane $\mathrm{e}^{\mathrm{a}, \mathrm{b}}$

\begin{tabular}{|c|c|c|c|c|c|c|}
\hline Carbene & alkene & $E_{\mathrm{a}}$ & $\Delta H^{\ddagger}$ & $\Delta S^{\ddagger}$ & $-\mathrm{T} \Delta S^{\dagger}$ & $\Delta G^{\dot{t}}$ \\
\hline \multirow[t]{4}{*}{$\mathrm{PhCCl}$} & TMeOE & -2.7 & -3.3 & -33 & 9.8 & 6.5 \\
\hline & & -5.3 & -5.9 & -41 & 12.2 & 6.3 \\
\hline & TME & -1.8 & -2.4 & -28 & 8.3 & 5.9 \\
\hline & & -5.2 & -5.8 & -40 & 11.9 & 6.1 \\
\hline \multirow[t]{4}{*}{$\mathrm{F}_{5}-\mathrm{PhCCl}$} & TMeOE & -3.2 & -3.8 & -32 & 9.5 & 5.7 \\
\hline & & -5.7 & -6.3 & -40 & 11.9 & 5.6 \\
\hline & TME & -1.8 & -2.4 & -26 & 7.7 & 5.3 \\
\hline & & -5.5 & -6.1 & -38 & 11.3 & 5.2 \\
\hline \multirow[t]{4}{*}{ 3,5-DN-PhCCl } & TMeOE & -6.0 & -6.6 & -40 & 11.9 & 5.3 \\
\hline & & $-10.4^{\mathrm{c}}$ & -11.0 & $-54^{c}$ & 16.1 & 5.1 \\
\hline & TME & -4.7 & -5.3 & -36 & 10.7 & 5.4 \\
\hline & & -8.0 & -8.6 & -46 & 13.7 & 5.1 \\
\hline
\end{tabular}

${ }^{a}$ Pentane data in black; decane data in red. ${ }^{b}$ Units are $\mathrm{kcal} / \mathrm{mol}$ for $E_{\mathrm{a}}, \Delta H^{\ddagger}$, -T $\Delta S^{\ddagger}$, and $\Delta G^{\ddagger}$; and cal$\mathrm{deg} / \mathrm{mol}$ for $\Delta S^{\ddagger} . \Delta H^{*}$ is calculated at $292 \mathrm{~K} ; \Delta G^{\ddagger}$ is calculated at $298 \mathrm{~K}$. Errors are generally less than $\pm 0.6 \mathrm{kcal} / \mathrm{mol}$ in $E_{\mathrm{a}}$; errors in $\Delta S^{\ddagger}$ are generally $\sim \pm 1$ e.u. ${ }^{\mathrm{c}}$ A repetition of this determination gave $E_{\mathrm{a}}=-10.0$ $\pm 0.6 \mathrm{kcal} / \mathrm{mol}$ and $\Delta S^{\sharp}=-53 \pm 2 \mathrm{eu}$. 
Several observations and conclusions can be extracted from the data in Table 1. (1) As anticipated, TMeOE is slightly more reactive than TME toward the three carbenes. Activation energies are more negative for carbene additions to TMeOE than TME, particularly in pentane. (2) Activation energies are more negative by $\sim 3-4 \mathrm{kcal} / \mathrm{mol}$ and activation entropies are more negative by 10-12 e.u. for additions in decane as opposed to pentane, in keeping with the operation of "solvent cages in decane.",

(3) Compensation is evident between $E_{\mathrm{a}}$ (or $\Delta H^{\ddagger}$ ) and $\Delta S^{\ddagger},{ }^{3}$ both decrease in tandem in response to the pentane to decane solvent change. As a result, the decrease in $\Delta H^{\ddagger}$ is offset by a comparable increase in $-\mathrm{T} \Delta S^{\ddagger}$, and there is very little overall change in $\Delta G^{\ddagger}$ as a consequence of the alteration of solvent. (4) The values of $E_{\mathrm{a}} \sim-10.4 \mathrm{kcal} / \mathrm{mol}$ and $\Delta S^{\ddagger}$ $\sim-54$ e.u. for the addition of 3,5-DN-PhCCl to TMeOE in decane solvent are the most negative yet encountered in any carbene-alkene addition reaction.

The experimental results do not distinguish between the two models proffered above to account for the observed negative activation energies. We carried out computational analyses of the carbene additions hoping to refine our mechanistic conception. For the carbene-alkene pairs PhCCl-TMeOE and 3,5-DN-PhCCl-TMeOE, we were able to locate the requisite stationary points on the respective potential energy surfaces that represent cycloaddition TS's or the formation of $\pi$-type complexes; however, all such searches were futile for the $\mathrm{F}_{5}-\mathrm{PhCCl}-\mathrm{TMeOE}$ pair (see Supplementary Data for minor elaboration). The TS's for cyclopropane formation are visualized in Figure 2; computed energetic data are shown in Table 2 (along with pertinent experimental data from Table 1). 


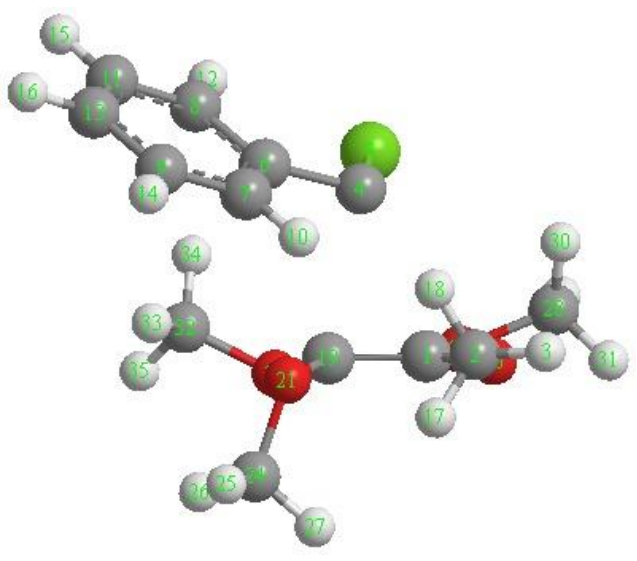

(a)

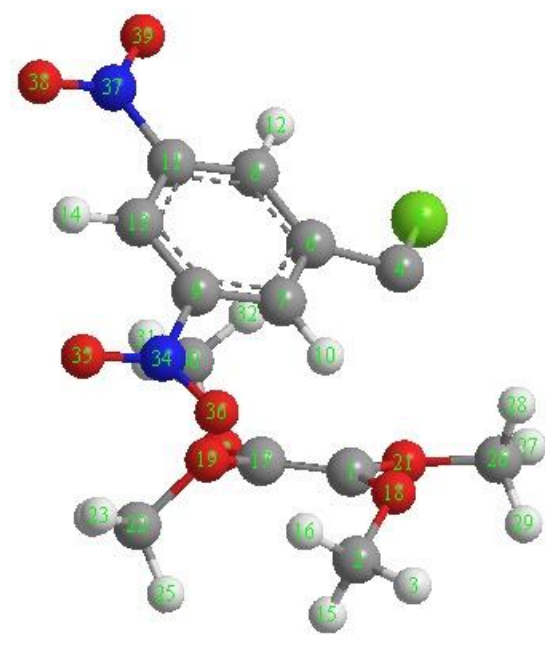

(b)

Figure 2. (a) TS for PhCCl-TMeOE cycloaddition. (b) TS for 3,5-DN-PhCCl-TMeOE cycloaddition .

The TS for PhCCl adding to TMeOE (Fig. 2a) is fairly conventional in appearance for a cycloaddition TS between a strongly nucleophilic alkene and an electrophilic carbene. The carbene carbon is positioned close to and almost equidistant between the two ethylenic carbons $(\mathrm{C} 4-\mathrm{C} 19=2.43 \AA, \mathrm{C} 4-\mathrm{C} 1=2.56 \AA)$, and there is a pronounced elongation of the ethylenic double bond $(\mathrm{C} 1-\mathrm{C} 19=1.38 \AA$ ). The angles formed between the carbenic carbon and the ethylene bond are similar (C1-C19-C4 = $\left.79.1^{\circ}, \mathrm{C} 4-\mathrm{C} 1-\mathrm{C} 19=68.9^{\circ}\right)$. In accord with the elongated $\mathrm{C}=\mathrm{C}$ bond, electron population analysis shows a substantial transfer of $0.39 \mathrm{e}$ from TMeOE to $\mathrm{PhCCl}$. The computed activation energy is $E_{\mathrm{a}}=-2.9 \mathrm{kcal} / \mathrm{mol}$ and compares extremely well to the measured value of $-2.7 \mathrm{kcal} / \mathrm{mol}$. The computed $\Delta S^{\ddagger}$ of -45 e.u. (assuming ideal gas conditions) is somewhat more negative than the measured value (-33 e.u.), and the computed $\Delta G^{\ddagger}$ of 9.9 $\mathrm{kcal} / \mathrm{mol}$ hence differs by ca. $3.5 \mathrm{kcal} / \mathrm{mol}$ from the experimental value. The 'imaginary' frequency characteristic of the curvature of the potential energy surface at the TS structure has a modest value of $106 \mathrm{~cm}^{-1}$.

In contrast, the TS for 3,5-DN-PhCCl-TMeOE cycloaddition (Fig. 2b) has the appearance of a very 'early' attack by a carbene on an alkene. The carbene carbon is far from the two ethylenic carbons $(\mathrm{C} 4-\mathrm{C} 17=3.57 \AA, \mathrm{C} 4-\mathrm{C} 1=3.14 \AA$ ) and the ethylenic double bond $(\mathrm{C} 1-\mathrm{C} 17=1.34 \AA)$ is fully intact. The angles formed between the carbenic carbon and the ethylene bond are highly asymmetric $\left(\mathrm{C} 4-\mathrm{C} 17-\mathrm{C} 1=45.2^{\circ}, \mathrm{C} 4-\mathrm{C} 1-\mathrm{C} 17=\right.$ 
$118.6^{\circ}$ ) and the carbenic center is positioned 'outside' the alkene bond. Population analysis indicates only a small transfer of $0.05 \mathrm{e}$ from $\mathrm{TMeOE}$ to $3,5-\mathrm{DN}-\mathrm{PhCCl}$ in the TS (cf. the unaltered length of the TMeOE double bond). The computed activation energy is $E_{\mathrm{a}}=-7.8 \mathrm{kcal} / \mathrm{mol}$ and compares very favorably to the measured value of $-6.0 \mathrm{kcal} / \mathrm{mol}$. The computed $\Delta S^{\ddagger}$ of -42 e.u. is surprisingly close to the measured value (-40 e.u.), and hence the computed $\Delta G^{\ddagger}$ of $4.1 \mathrm{kcal} / \mathrm{mol}$ differs only by ca. $1.2 \mathrm{kcal} / \mathrm{mol}$ from the experimental value. The 'imaginary’ frequency of the TS is very small $\left(34 \mathrm{i} \mathrm{cm}^{-1}\right)$, indicating that the potential energy surface is extremely flat in the TS region.

Table 2.

Computed parameters for carbene additions to TMeOE in pentane $\mathrm{e}^{\mathrm{a}, \mathrm{b}}$

\begin{tabular}{|c|c|c|c|c|c|}
\hline species & $\Delta E, E_{\mathrm{a}}$ & $\Delta H, \Delta H^{\ddagger}$ & $\Delta S, \Delta S^{\ddagger}$ & $-\mathrm{T} \Delta S,-\mathrm{T} \Delta S^{\ddagger}$ & $\Delta G, \Delta G^{\ddagger}$ \\
\hline $\mathrm{PhCCl}+\mathrm{TMeOE}$ & 0.0 & 0.0 & 0.0 & 0.0 & 0.0 \\
\hline 'O-ylidic' complex ${ }^{\mathrm{c}}$ & -6.4 & -5.2 & -32 & 9.5 & 4.3 \\
\hline$\pi$-complex ${ }^{\mathrm{c}}$ & -5.6 & -4.4 & -30 & 9.0 & 4.7 \\
\hline $\mathrm{TS}$, calc $^{\mathrm{d}}$ & -2.9 & -3.5 & -45 & 13.4 & 9.9 \\
\hline $\mathrm{TS}, \exp ^{\mathrm{d}, \mathrm{e}}$ & -2.7 & -3.3 & -33 & 9.8 & 6.5 \\
\hline Cyclopropane $^{\mathrm{c}}$ & -66.4 & -63.7 & -46 & 13.8 & -49.9 \\
\hline 3,5-DN-PhCCl + TMeOE & 0.0 & 0.0 & 0.0 & 0.0 & 0.0 \\
\hline 'O-ylidic' complex ${ }^{\mathrm{c}}$ & -12.8 & -11.2 & -38 & 11.5 & 0.3 \\
\hline$\pi$-complex ${ }^{\mathrm{c}}$ & -12.4 & -10.8 & -39 & 11.8 & 1.0 \\
\hline $\mathrm{TS}$, calc $^{\mathrm{d}}$ & -7.8 & -8.4 & -42 & 12.5 & 4.1 \\
\hline $\mathrm{TS}, \exp ^{\mathrm{d}, \mathrm{e}}$ & -6.0 & -6.6 & -40 & 11.9 & 5.3 \\
\hline Cyclopropane $^{\mathrm{c}}$ & -73.8 & -70.7 & -49 & 14.5 & -56.2 \\
\hline
\end{tabular}

${ }^{\mathrm{a}}$ Units are $\mathrm{kcal} / \mathrm{mol}$ for all energies but cal-deg/mol (eu) for $\Delta S^{\ddagger} . E_{\mathrm{a}}=\Delta H^{\sharp}+\mathrm{RT}$. ${ }^{\mathrm{b}} \mathrm{T}=298 \mathrm{~K}$. ${ }^{\mathrm{c}} \mathrm{For}{ }^{\circ} O$ ylidic'complexes, $\pi$-complexes, and cyclopropanes, $\Delta E$ refers to the difference in potential energy between the species and the free reactants; $\Delta H, \Delta S$, $-\mathrm{T} \Delta S$, and $\Delta G$ pertain to these species. ${ }^{\mathrm{d}}$ Transition states; $E \mathrm{a}, \Delta H^{\sharp}, \Delta S^{\sharp},-\mathrm{T} \Delta S^{\sharp}, \Delta G^{\sharp}$ pertain to these species. ${ }^{\mathrm{e}}$ Experimental values; see Table 1. 
We have also located examples of a second type of bimolecular carbene-TMeOE complex, illustrated in Figure 3, which we label as $\pi$-complexes. In the PhCCl-TMeOE $\pi$-complex (Fig. 3a), the dominant interaction occurs between the formally empty carbene $2 \mathrm{p}$ orbital and the ethylenic $\pi$-bond, whereas for the $3,5-\mathrm{DN}-\mathrm{PhCCl}-\mathrm{TMeOE} \pi$ complex (Fig. 3b) significant interactions materialize between the alkene double bond and the aryl group and also between an oxygen lone pair and the carbene $2 \mathrm{p}$ orbital. ${ }^{20}$

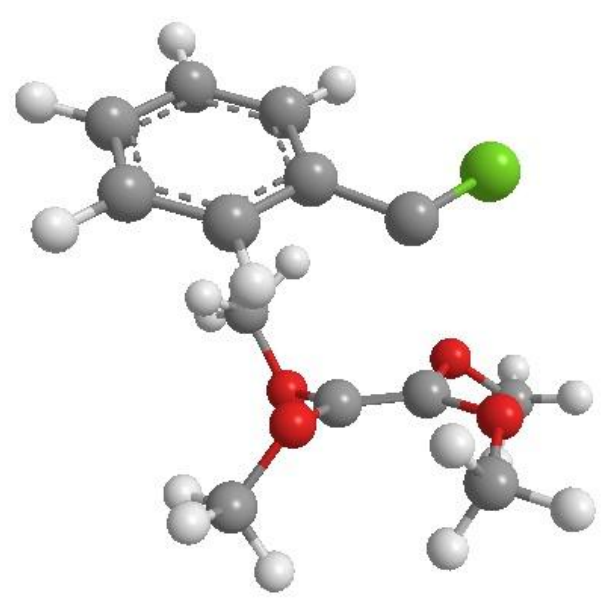

(a)

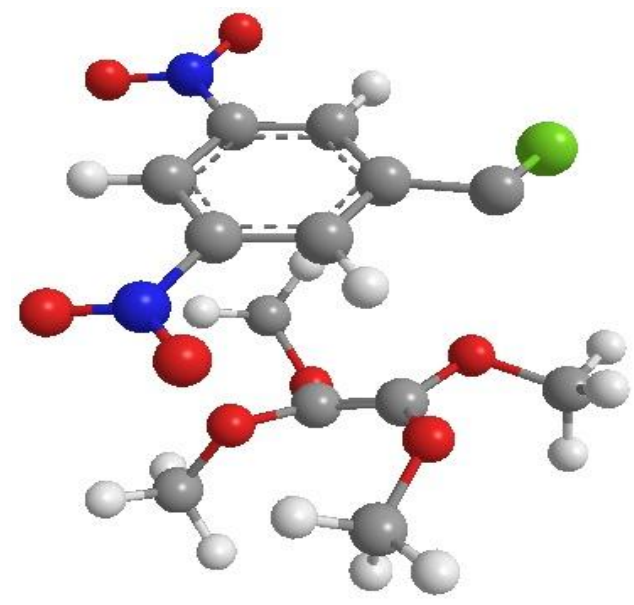

(b)

Figure 3. (a) PhCCl-TMeOE $\pi$-complex. (b) 3,5-DN-PhCCl-TMeOE $\pi$-complex.

Naturally, cyclopropane formation resulting from $\mathrm{PhCCl}$ or 3,5-DN-PhCCl addition to TMeOE is a highly exothermic process (computed $\Delta H_{\mathrm{rx}}=63.7 \mathrm{kcal} / \mathrm{mol}$ and $70.7 \mathrm{kcal} / \mathrm{mol}$ for $\mathrm{PhCCl}-\mathrm{TMeOE}$ and 3,5-DN-PhCCl-TMeOE, respectively; Table 2). These 'steep down-hill' or perhaps even 'cliff-like' features of the potential energy surfaces, which to some extent manifest themselves in the phenomena of negative activation enthalpies, significantly complicate computational identifications of the structurally and energetically similar $\pi$-complexes and transition states for cycloaddition. ${ }^{21}$ However, we may take advantage of the special topological features attributed to a genuine TS as a first-order saddle point on the potential energy surface. Thus, following the intrinsic reaction coordinate (IRC) from the TS in, say, the 'forward' direction leads directly to the appropriate cyclopropane, whereas careful IRC following in the 'reverse' direction (incremental step lengths significantly reduced from their default 
values) does lead to the $\pi$-complex. Consequently, the $\pi$-complexes are intermediates on the reaction coordinate for cycloaddition. They are positioned slightly before the TS and are only ca. $2 \mathrm{kcal} / \mathrm{mol}$ below the corresponding TS in enthalpy; differences in free energy are modestly larger $(3-5 \mathrm{kcal} / \mathrm{mol})$ because the entropic penalties when forming the $\pi$-complexes are slightly less. Despite the reduced $-\mathrm{T} \Delta S$ term, $\Delta G$ for $\pi$-complex formation is positive by a few $\mathrm{kcal} / \mathrm{mol}$, so the equilibrium constant must be correspondingly small $\left(K \sim 10^{-1}\right.$ or less). With the $\pi$-complexes sitting in a shallow basin of limited spatial extent, their importance for the kinetics of cyclopropane formation should be very limited or nil.

We suggest that specific solvation and solvent cage formation both contribute to measured $E_{\mathrm{a}}$ 's that are 3-4 kcal/mol lower in decane than pentane. ${ }^{22}$ By a "cage" we imply an enthalpy-driven ensemble of at least two decane molecules simultaneously solvating an encounter complex of $\mathrm{ArCCl}$ and $\mathrm{TMeOE}$, with mutual cohesion provided by non-covalent forces. Arylhalocarbenes do bind more strongly to a molecule of decane than to a pentane molecule, evidently because of the larger number of methylene groups available for interaction with the carbene $\pi$-system ( 5 vs 3; all-trans alkane configurations; see Supplementary Data for pictures). The computed binding enthalpies for a decane molecule with $\mathrm{PhCCl}$ or $3,5-\mathrm{DN}-\mathrm{PhCCl}$ are $4.5 \mathrm{kcal} / \mathrm{mol}$ and $6.5 \mathrm{kcal} / \mathrm{mol}$, respectively; with a pentane molecule, the corresponding values are $3.9 \mathrm{kcal} / \mathrm{mol}$ and 4.9 $\mathrm{kcal} / \mathrm{mol}$. Similarly, TMeOE may adhere to pentane or decane molecules through $\mathrm{H}$ bonding $(\mathrm{C}-\mathrm{H}-\mathrm{O}$ interaction); we find computed binding enthalpies of $2.3 \mathrm{kcal} / \mathrm{mol}$ and $5.1 \mathrm{kcal} / \mathrm{mol}$, respectively. Accordingly, we infer that all species, and in particular the $\pi$ complexes and TS's for cycloaddition, will be preferentially stabilized enthalpically in decane (vs pentane). Enthalpic stabilization of the TS suggests a move toward a 'tighter' TS, a TS occurring later along the reaction coordinate being closer to the products in structure. We simulate tightening of the TS by displacing the TS structure along the transition vector, the normal mode in the TS that corresponds to the 'imaginary' frequency. In the case of $\mathrm{PhCCl}$, moving the TS manually by one half rms displacement reduces the energy by $1.4 \mathrm{kcal} / \mathrm{mol}$; moving the TS by a full $\mathrm{rms}$ displacement lowers the energy dramatically by $9.7 \mathrm{kcal} / \mathrm{mol}$, illustrating the abrupt decrease in the potential energy along the reaction coordinate after the TS has been traversed. ${ }^{23}$ Although far from 
being conclusive, these computational experiments do suggest that seemingly small perturbations to the TS may engender a substantial energetic response.

In conclusion, the activation energy for $3,5-\mathrm{DN}-\mathrm{PhCCl}$ addition to $\mathrm{TMeOE}$ in decane $\left(E_{\mathrm{a}} \sim-10 \mathrm{kcal} / \mathrm{mol}\right)$ is the most negative activation energy yet observed for carbene-alkene addition reactions. Our experimental results do not distinguish per se between the two models commonly proposed for such observations, but the computational results clearly favor the model proposed by Houk et al. ${ }^{8-10}$ Overall, the potential energy surface is very attractive toward arylhalocarbene-TMeOE interaction. In particular, the energy and hence the enthalpy decreases rapidly along the reaction coordinate for cycloaddition, so rapidly that in solution at ambient temperature the reactants may well entirely skirt the shallow $\pi$-complex minima predicted in the calculations. We caution that our mechanistic conclusions are based on measurements of rates and the computational characterization of a few stationary points on potential energy surfaces. Dynamical effects are ignored and realistic evaluations of, for example, the solvation of highly reactive species and condensed phase entropies are not possible. ${ }^{24}$ Nevertheless, the agreement between measured and computed quantities for these challenging reactions, as exemplified in Table 2, is noteworthy and indicates, at least minimally, that the gross chemical and physical features of these carbene-alkene additions are properly treated by our straightforward models.

\section{Acknowledgements}

We thank Dr. Hui Cang for an initial preparation of TMeOE. We are grateful to Rutgers University and the U.S. National Science Foundation for financial support.

\section{Supplementary Data}

Supplementary Data associated with this article can be found in the online version at 


\section{References and notes}

1. Turro, N. J.; Lehr, G. F.; Butcher, J. A., Jr.; Moss, R. A.; Guo, W. J. Am. Chem. Soc. 1982, 104, 1754-1756.

2. Moss, R. A.; Wang, L.; Zhang, M.; Skalit, C.; Krogh-Jespersen, K. J. Am. Chem. Soc. 2008, 130, 5634-5635.

3. Wang, L.; Krogh-Jespersen, K.; Moss, R. A. J. Org. Chem. 2015, 80, 7590-7593.

4. Moss, R. A.; Wang, L.; Krogh-Jespersen, K. J. Am. Chem. Soc. 2014, 136, 4885-4888.

5. Cang, H.; Moss, R. A.; Krogh-Jespersen, K. J. Am. Chem. Soc. 2015, 137, 2730-2737.

6. Gould, I. R.; Turro, N. J.; Moss, R. A. et al. Tetrahedron 1985, 41, 1587-1600.

7. Moss, R. A.; Lawrynowicz, W.; Turro, N. J.; Gould, I. R.; Cha, Y. J. Am. Chem. Soc. 1986, 108, 7028-7032.

8. Houk, K. N.; Rondan, N. G.; Mareda, J. J. Am. Chem. Soc. 1984, 106, 4291-4293.

9. Houk, K. N.; Rondan, N. G. J. Am. Chem. Soc. 1984, 106, 4293-4294.

10. Houk, K. N.; Rondan, N. G. Tetrahedron 1985, 41, 1555-1563.

11. Moss, R. A.; Wang, L.; Krogh-Jespersen, K. Tetrahedron Lett. 2014, 55, 6016-6018.

12. Wang, L.; Moss, R. A.; Krogh-Jespersen, K. in preparation.

13 (a) Moss, R. A. Acc. Chem. Res. 1980, 13, 58-64; (b) Rondan, N. G.; Houk, K. N.; Moss, R.A. J. Am. Chem. Soc. 1980, 102, 1770-1776.

14. Muchall, H. M.; Werstiuk, N. H.; Choudhury, B.; Ma, J.; Warkentin, J.; Pezacki, J. P. Can, J. Chem. 1998, 76, 238-240.

15. Mintz, D. A.; Kuppermann, A. J. Chem. Phys. 1979, 71, 3499-3513.

16. Nevertheless, additions of $\mathrm{PhCCl}, \mathrm{F}_{5}-\mathrm{PhCCl}$, or 3,5-DN-PhCCl to TMeOE in pentane are computed to be $4-6 \mathrm{kcal} / \mathrm{mol}$ less exothermic than the analogous additions to TME. This is likely due to the arrangement of the methoxy groups in the product cyclopropanes, relative to their optimal arrangement in TMeOE. The conformer of lowest energy for TMeOE exhibits $\mathrm{D}_{2}$ molecular symmetry in which the Me group of each methoxy group is anti to its neighbor. This orientation of $\mathrm{MeO}$ groups cannot be preserved in the product cyclopropanes.

17. (a) Scheeren, J. W.; Staps, R. J. F. M.; Nivard, R. J. F. Rec. Trav. Chim. 1973, 92, 1119; (b) Scheeren, J. W.; Stevens, W. Rec. Trav. Chim. 1966, 85, 793-799. 
18. For a detailed description of this installation, see Moss, R. A.; Wang, L.; KroghJespersen, K. J. Org. Chem. 2013, 78, 11040-11044.

19. For additions to TMeOE: 3 carbenes $\mathrm{x} 5$ temperatures $\mathrm{x} 2$ solvents $=30$ rate constants. For additions to TME: 3 carbenes $x$ temperatures in decane $=15$ rate constants. The corresponding rate constants in pentane are taken from ref. 3.

20. In fact, the $\pi$ - and $O$-ylidic complexes are structurally quite similar in the case of 3,5$\mathrm{DN}-\mathrm{PhCCl}$ and TMeOE.

21. Standard procedures which invoke chemical intuition to create suitable initial structures, followed by geometry optimization toward a proper stationary point (minimum or TS) led in many, many trials to structural collapse and cyclopropane formation; search convergence was typically slow and often required user intervention to be successful. Formation of the product cyclopropane invariably occurred in computations of the reaction pathway for $\mathrm{F}_{5}-\mathrm{PhCCl}$ and $\mathrm{TMeOE}$.

22. Continuum dielectric models are inherently unable to make a significant distinction between solvation in pentane or decane because the dielectric constants for pentane (eps $=1.8371)$ and decane (eps $=1.9846)$ are very similar. Therefore, the computed energetic differences are less than $1 \mathrm{kcal} / \mathrm{mol}$ upon change of the model solvent from pentane to decane.

23. This approach to simulating a 'tighter' TS did not produce useful results for 3,5-DN$\mathrm{PhCCl}$ addition to TMeOE, where the imaginary frequency is only $34 \mathrm{i} \mathrm{cm}^{-1}$. The rms displacement for the transition vector when the carbene is $3,5-\mathrm{DN}-\mathrm{PhCCl}$ is smaller than in the case of $\mathrm{PhCCl}$, where the frequency is $106 \mathrm{~cm}^{-1}$. Whereas the latter TS is rather conventional in appearance (cf. Fig 2a) and the transition vector shows distinct changes in inter-atomic distances between the $\mathrm{PhCCl}$ and $\mathrm{TMeOE}$ units, the transition vector for the cycloaddition TS between 3,5-DN-PhCCl and TMeOE involves considerable rotation of the arylhalocarbene relative to the alkene (cf. Fig 2b).

24. Carpenter, B. K.; Harvey, J. N.; Orr-Ewing, A. J. J. Am. Chem. Soc. 2016, 138, 46954705. 
GRAPHICAL ABSTRACT

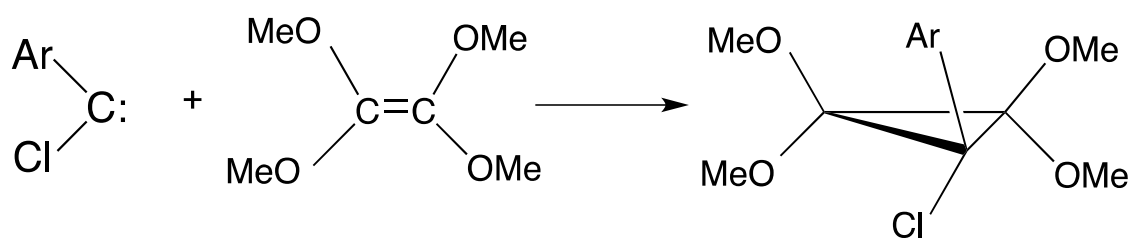

